Microporous and Mesoporous Materials 171 (2013) 131-138

DOI: $10.1016 /$ j.micromeso.2012.12.037

\title{
Indometacin loading and in vitro release properties from novel carbopol coated spherical mesoporous silica nanoparticles
}

\author{
Borislav Tzankov ${ }^{\mathrm{a}}$, Krassimira Yoncheva ${ }^{\mathrm{a}}$, Margarita Popova ${ }^{\mathrm{b}}$, Agnes Szegedic, Georgi \\ Momekov $^{a}$, Judith Mihályc, Nicolai Lambov ${ }^{\mathrm{a}}$ \\ ${ }^{a}$ Faculty of Pharmacy, 2 Dunav Str., 1000 Sofia, Bulgaria \\ ${ }^{b}$ Institute of Organic Chemistry with Centre of Phytochemistry, Bulgarian Academy of \\ Sciences, Sofia, Bulgaria \\ ${ }^{\mathrm{c}}$ Research Centre for Natural Sciences, Institute of Materials and Environmental Chemistry, \\ Hungarian Academy of Sciences, 1025 Budapest, Pusztaszeri út. 59-67, Hungary
}

Keywords: Spherical mesoporous silica, Indometacin release, Carbopol coating, Cytotoxicity

\begin{abstract}
Spherical MCM-41 silica nanosized particles were synthesized and post synthesis modified by 3-aminopropyltriethoxysilane (APTES) in order to prepare amino-functionalized carrier. Both types of silica particleswere loaded with indometacin and further coated with carbopol. The preservation of morphology and pore structure of the particles was observed by XRD, TEM and $\mathrm{N}_{2}$ physisorption. FT-IR spectroscopy revealed the interaction between carboxyl groups of indometacin and the amino groups of the functionalized MCM-41. Amino-functionalization of the carrier resulted in higher degree of indometacin loading in comparison to the parent MCM$41,39 \%$ vs. $30 \%$, respectively. The coating of drug loaded amino-MCM-41 silica particles with carbopol significantly reduced the initial burst release of indometacin. Both silica carriers demonstrated no cytotoxicity on HL-60 (acute myeloid leukemia) and K-562 (chronic myeloid leukemia) cell lines.
\end{abstract}

\section{Introduction}

Mesoporous silica materials are in focus of research due to their porous structure and high surface area. Recently, research has been focused on the application of mesoporous silica based materials as a potential drug delivery system [1-5]. Their excellent biocompatibility and the capability to be functionalized with different organic groups make them attractive candidates for a wide range of biomedical purposes, such as controlled drug delivery [6,7]. The most often used mesoporous silica based drug carrier has been the ordered hexagonal MCM-41 molecular sieve. The appropriate chemical modification of the surface of the mesoporous matrix could enhance the adsorption of drug molecules [3,8]. Modification of MCM-41 by different organic groups (amino, carboxyl, chloropropyl, phenyl, benzyl, mercaptopropyl, cyanopropyl, butyl groups etc.) improved the drug loading due to the eventual interactions with the functional groups of the drug. Further, the formation of bonds could overcome the problems associated with the burst release of the incorporated drug molecule [3]. Doadrio et al. have reported that erythromycin release from functionalized matrices was much slower compared to unmodified material [9]. Basaldella and Legnoverde have reported that the initial release of cephalexin was not influenced by functionalization of SBA-15 carrier but the second stage of the release was 
significantly influenced [10]. On the other hand, the undesired burst release of the drug molecule incorporated into mesoporous particles could be avoided by coating or capping the pores of the particles. In the recent years drug release has been controlled by closing the pore entrances with $\mathrm{CdS}$, gold nanoparticle caps, or silica nanoparticles were covered by $\mathrm{pH}$ and temperature sensitive coatings [11-18]. For instance, capping the pores by $\mathrm{CdS}$ nanoparticles via a chemically cleavable disulfide link hindered the initial release of the entrapped drug [11]. Poly(acrylic acid) and poly(methacrylic acid) were grafted on the surface of mesoporous silica particles in order to provide $\mathrm{pH}$-controlled drug release [16,17]. You et al. [18] have reported temperature-controlled release systems applying a temperature-responsive polymer. Coating with bioadhesive polymers could be considered as a new direction of research that is still in the initial stage. In our opinion, formation of a bioadhesive polymer coating layer around nanoparticles could hinder the rapid burst release of the loaded drug as well as to promote the interactions between gastrointestinal mucosa and nanoparticles. The latter is closely related with a prolongation of gastrointestinal residence of the drug-loaded particles and an eventual subsequent improvement of oral bioavailability, especially for poorly soluble drugs.

Indometacin is an acidic non-steroidal anti-inflammatory drug causing irritation of the gastrointestinal mucosa [19]. The side effects have been considered as combination of local irritation due to the direct contact of free carboxyl group of indometacin and local inhibition of cytoprotective action of prostaglandins on gastric mucosa [20]. Some researchers have developed indometacin prodrugs that reduced the occurrence of the side effects due to esterification of the carboxyl groups of indometacin and their slow hydrolysis in gastrointestinal tract [21]. However, the development of the pro-drugs requires optimal protection of the drug until it reaches the desired site to by hydrolyzed.

The aim of the present study was to prevent the initial contact between indometacin and gastrointestinal mucosa by its incorporation into the pores of the mesoporous silica particles. Aminofunctionalized $\mathrm{MCM}-41 \mathrm{NH}_{2}$ carrier was prepared aiming to bind the carboxyl group of indometacin and to improve drug loading degree. The concept of silica functionalization was combined with the post-coating of the mesoporous particles with a polymer in order to avoid burst release of the loaded drug. Carbopol was selected as coating polymer taking into account the eventual electrostatic interaction between its carboxylic groups and amino groups located on the surface of the functionalized carrier. In addition, the coating of mesoporous silica nanoparticles with carbopol could promote bioadhesive interactions between the modified particles and the cells of gastrointestinal mucosa being a very important factor for drug bioavailability.

\section{Experimental}

\subsection{Synthesis of MCM-41 spherical silica materials}

Spherical nanosized MCM-41 particles were prepared according to the procedure of Huh et al. [22]. This sol-gel procedure is carried out at $353 \mathrm{~K}$ without co-solvent, only in water solution and with $\mathrm{NaOH}$ as a catalyst. The relative molar composition of the reaction mixture was:

1 TEOS: $0.12 \mathrm{C}_{16}$ TMABr: $0.31 \mathrm{NaOH}: 1190 \mathrm{H}_{2} \mathrm{O}$.

The formed gel was aged at $353 \mathrm{~K}$ for $2 \mathrm{~h}$, than washed with distilled water until neutral $\mathrm{pH}$, and dried at ambient. Template removal of MCM-41 materials was carried out in air at $823 \mathrm{~K}$ with $1 \mathrm{~K} / \mathrm{min}$ rate for $5 \mathrm{~h}$. 


\subsection{Modification of the materials by APTES}

Modification of the spherical MCM-41 material with amino groups was accomplished by reaction with 3-aminopropyltriethoxysilane (APTES) in toluene (333 K, $24 \mathrm{~h}$ ). Following the reaction samples were washed with several portions of toluene, methanol and finally water. 20 $\mathrm{ml}$ APTES in $100 \mathrm{ml}$ toluene was applied to $1 \mathrm{~g}$ of silica. The APTES modified samples were designated as MCM-41 $\mathrm{NH}_{2}$.

\subsection{Indometacin loading and carbopol coating of parent MCM-41 and amino-functionalized MCM-41NH $\mathrm{N}_{2}$ samples}

Indometacin and powdered mesoporous samples were incubated into ethanol under continuous magnetic stirring for $24 \mathrm{~h}$ at $310 \mathrm{~K}$. In particular, $100 \mathrm{mg}$ of indometacin was dissolved in $10 \mathrm{ml}$ of ethanol and $100 \mathrm{mg}$ of dried mesoporous silica was put into this solution. After incubation for $24 \mathrm{~h}$, the mixture was centrifuged at $15,000 \mathrm{rpm}$, rinsed with purified water, separated by a second centrifugation, and finely dried at room temperature under vacuum. The samples were abbreviated as MCM-41IND and MCM-41 $\mathrm{NH}_{2} \mathrm{IND}$, respectively.

Drug loaded MCM-41IND or amino-functionalized MCM-41 $\mathrm{NH}_{2} \mathrm{IND}$ particles were incubated in an queous phase containing carbopol $(0.012 \% \mathrm{wt}$.) under gentle stirring $(100 \mathrm{rpm})$ for $2 \mathrm{~h}$. After incubation, the dispersions were centrifuged at 15,000 rpm for $15 \mathrm{~min}$, rinsed with distilled water, separated by a second centrifugation, and finely dried at room temperature under vacuum. The amount of indometacin in the supernatants was measured by UVspectrophotometry at a wavelength of $320 \mathrm{~nm}$ (Hewlet Packard 8452A). The samples were abreviated as MCM-41INDC and MCM-41 $\mathrm{NH}_{2} \mathrm{INDC}$, respectively.

\subsection{Characterization of the samples}

X-ray diffractograms were recorded by a Philips PW 1810/3710 diffractometer with BreggBrentano parafocusing geometry applying monochromatized $\mathrm{Cu} \mathrm{Ka}(\lambda=0.15418 \mathrm{~nm})$ radiation $(40 \mathrm{kV}, 35 \mathrm{~mA})$ and a proportional counter.

Nitrogen physisorption measurements were carried out at $77 \mathrm{~K}$ using Quantachrome NOVA Automated Gas Sorption Instrument. The pore-size distribution was calculated from the desorption branch of the isotherms with the BJH method. Pure silica samples were pre-treated at $623 \mathrm{~K}$, whereas amino modified and drug loaded materials at $353 \mathrm{~K}$ for $5 \mathrm{~h}$ before measurements.

Attenuated Total Reflection Infrared (ATR-FTIR) spectra were recorded by means of a Varian Scimitar 2000 FTIR spectrometer equipped with a MCT (mercury-cadmium-tellur) detector and a single reflection ATR unit (SPECAC "Golden Gate") with diamond ATR element. In general, 128 scans and $4 \mathrm{~cm}^{-1}$ resolution were applied. For all spectra ATR-correction was performed (Varian ResPro 4.0 software).

NMR spectra were recorded on a Bruker Avance II +600 NMR spectrometer operating at $600.13 \mathrm{MHz}$ proton frequency (150.90 MHz for 13C), using $4 \mathrm{~mm}$ solid state CP/MAS dual probe head. The samples were loaded in $4 \mathrm{~mm}$ zirconia rotors and spun at magic angle spinning (MAS) rate of $6 \mathrm{kHz}$ in all experiments. 13C NMR spectra were acquired with $8 \mathrm{~K}$ time domain data points, spectrum width of $50 \mathrm{kHz}, 256$ scans and a recycle delay of $5 \mathrm{~s}$, using a cross polarization pulse sequence with total suppression of side bands (cptoss) from Bruker Topspin library. The spectra were processed with an exponential window function (line broadening factor 10) and zero filled to $16 \mathrm{~K}$ data points.

TEM images were taken by using a MORGAGNI 268D TEM $(100 \mathrm{kV}$; W filament; pointresolution $=0.5 \mathrm{~nm})$. 
The thermogravimetric measurements were performed with a Setaram TG92 instrument with a heating rate of $5 \mathrm{~K} / \mathrm{min}$ in nitrogen flow.

Determination of nanoparticle size was performed using a Zetasizer (Zetasizer Nano ZS, Malvern Instruments, Worcestershire, UK). The samples were dispersed in distilled water and measuredat scattering angles of $90^{\circ}$ at $298 \mathrm{~K}$.

\subsection{In vitro release studies}

For in vitro release studies, $10 \mathrm{mg}$ of the drug loaded silica particles were incubated in 200 $\mathrm{ml}$ simulated gastric $(\mathrm{pH}=1.2)$ or simulated intestinal fluid $(\mathrm{pH}=6.8)$ at $310 \mathrm{~K}$ under stirring $(100 \mathrm{rpm})$. At appropriate time intervals, $5 \mathrm{ml}$ samples were withdrawn and replaced by fresh buffer. The withdrawn samples were centrifuged at $15,000 \mathrm{rpm}$ for $15 \mathrm{~min}$ and the concentration of the released indomethacin into the supernatant was determined by UVspectrophotometry at a wavelength of $320 \mathrm{~nm}$ (Hewllet Packard 8452A).

\subsection{In vitro cytotoxicity assay}

The cell lines HL-60 (acute myeloid leukemia) and K-562 (chronic myeloid leukemia) were purchased from the German Collection of Microorganism and Cell Cultures (DSMZ), Germany. Both cell lines were cultured in RPMI-1640 medium supplemented with $10 \%$ heat-inactivated fetal calf serum and L-glutamine. They were incubated in a controlled environment $(310 \mathrm{~K}, 5 \%$ carbon dioxide humidified atmosphere).

The cellular viability was chosen as a cytotoxicity end-point and determined using the 3(4,5-dimethylthiazol-2-yl)-2,5-diphenyltetrazolium bromide (MTT) dye reduction assay. The MTT assay was applied to evaluate the effect of the free carriers or drug loaded carriers, as well as that of the non-loaded indometacin on cell survival by measuring the uptake and reduction of tetrazolium salt to an insoluble formazan dye by mitochondrial succinate dehydrogenase in viable cells. One hundred microliter aliquotes of exponentially growing suspension cultures (1 x $10^{5}$ cells) was seeded into 96-well plates, whereas for each treatment group a set of 6 wells was used. The cells were incubated overnight and were exposed either to the free carriers, to free indometacin or indometacin loaded samples and incubated at $310 \mathrm{~K}$ for $72 \mathrm{~h}$. The carrier/culture medium suspensions contained the same drug concentrations as free indometacin $(12.5-200 \mu \mathrm{g} / \mathrm{ml})$. Non treated cells were used as control. After the exposure period $100 \mu \mathrm{l}$ of MTT $(1 \mathrm{mg} / \mathrm{ml})$ solution was added into each well and the plates were incubated at $310 \mathrm{~K}$ for 4 $\mathrm{h}$ to allow MTT-formazan formation. Then formazan crystals were solubilized through addition of $110 \mu \mathrm{HCOOH}(5 \%)$ acidified 2-propanol. Finally, absorption at $570 \mathrm{~nm}$ was measured with a Labexim LMR-1 Microplate Reader 3550 (Bio-Rad, USA).

The cell viability was calculated by the following formula: cell viability $(\%)=$ optical density (OD) of the treated cells/OD of the non-treated cells x 100 .

All data were arranged as mean \pm standard deviation. Significant differences were determined by t-test. $\mathrm{P}<0.05$ was considered to be significant.

\section{Results and discussion}

In this study mesoporous silica nanoparticles with improved drug loading properties were developed, exploiting the electrostatic interaction between amino-functionalized silica carrier and indometacin containing carboxyl functional groups. Taking into account that one of the main problems of these systems is the initial burst release of the drug, post-coating of the drug loaded mesoporous silica nanoparticles with carbopol was applied. Carbopol was selected as a coating polymer presuming that for in vivo studies the bioadhesion of the carbopol-coated 
mesoporous silica nanoparticles will be prerequisite for an improved oral bioavailability of the loaded drug.

\subsection{Physico-chemical characterization of the mesoporous materials}

XRD data of the MCM-41 samples with the intense (100) and higher Miller indices reflections in the low 2 theta region confirmed the preservation of the hexagonal structure upon aminofunctionalization and drug loading (Fig. 1). However, some broadening and intensity decrease were observed for all amino-functionalized mesoporous samples (MCM-41NH MCM-41NH2IND and MCM-41NH ${ }_{2}$ INDC) (Fig. 1). This effect can be considered as indication for some structural disorder which occurred during the functionalization procedure. Consequently, drug loading and carbopol coating procedure did not influence significantly the structural order of mesoporous carrier.

Also, the presence of crystalline indometacin phase was registered on the initial MCM-41 and the amino-functionalized $\mathrm{MCM}-41 \mathrm{NH}_{2}$ samples. This evidenced that indometacin was not only contained in the mesopore channels, but could be found on the outer surface of the small spherical particles or in the secondary mesopores, e.g. in the voids among the particles. In contrast, the coating with carbopol resulted in total disappearance of crystalline indometacin on the outer mesoporous surface of both indometacin loaded samples (MCM-41INDC and MCM$\left.41 \mathrm{NH}_{2} \mathrm{INDC}\right)$. These data presumed the formation of carbopol coating layer around the mesoporous nanoparticles.

Nitrogen adsorption and desorption isotherms of the parent, amino-functionalized and indometacin loaded samples are presented in Fig. 2 and the calculated textural parameters are presented in Table 1.

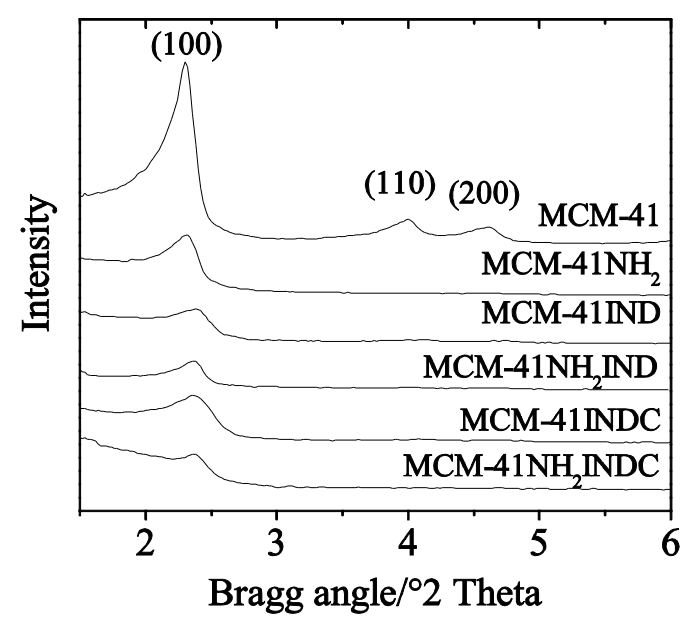

Fig.1. XRD patterns of the parent MCM-41, amino-functionalized $\mathrm{MCM}-41 \mathrm{NH}_{2}$ materials, and their indometacin loaded and carbopol-coated derivatives (MCM-41IND, MCM-41INDC, MCM-41NH $\mathrm{N}_{2} \mathrm{IND}$ and MCM-41 $\mathrm{NH}_{2}$ INDC). 


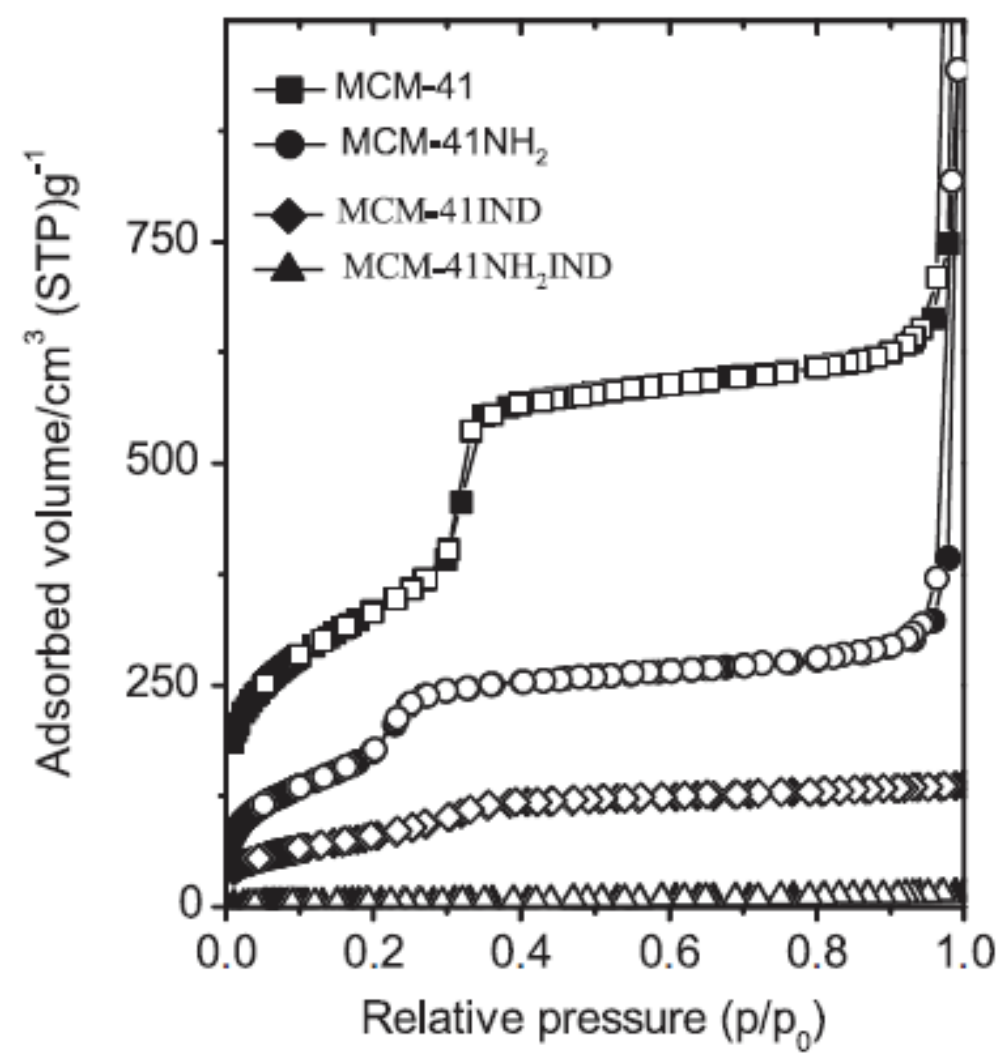

Fig. 2. Nitrogen adsorption/desorption isotherms of the parent, the aminofunctionalized, and indometacin loaded materials.

Table 1

Physicochemical properties of the parent (MCM-41), amino modified (MCM-41NH $\left.\mathrm{N}_{2}\right)$ and indometacin loaded MCM-41IND and MCM-41 $\mathrm{NH}_{2} \mathrm{IND}$ samples.

\begin{tabular}{|c|c|c|c|c|}
\hline Samples & $\mathrm{a}_{\mathrm{o}}{ }^{\mathrm{a}}(\mathrm{nm})$ & $\operatorname{BET}\left(\mathrm{m}^{2} / \mathrm{g}\right)$ & $\mathrm{PD}^{\mathrm{b}}(\mathrm{nm})$ & Pore volume $\left(\mathrm{cm}^{3} / \mathrm{g}\right)$ \\
\hline MCM-41 & 4.43 & 1175 & 2.7 & 0.99 \\
\hline $\mathrm{MCM}-41 \mathrm{NH}_{2}$ & 4.40 & 570 & 2.2 & 0.47 \\
\hline MCM-41IND & 4.34 & 213 & 2.7 & 0.20 \\
\hline MCM-41NH ${ }_{2}$ IND & 4.31 & 20 & n.d. & n.d. \\
\hline
\end{tabular}

${ }^{\text {a }}$ Cell parameter $\left(\mathrm{a}_{0}=2 \mathrm{~d}_{100}(3)^{1 / 2}\right)$.

${ }^{\mathrm{b}}$ Pore diameter and pore volume calculated by BJH method.

The isotherms of the parent and amino MCM-41 exhibited a sharp increase at a relative pressure of $p / p_{0}=0.2-0.4$, which was associated with capillary condensation of nitrogen in the channels and with a narrow pore size distribution (Fig. 2). The isotherms of the MCM-41 samples were reversible and did not show any hysteresis loop. The textural parameters of the parent MCM-41 sample loaded with indometacin showed significant decrease in the surface area, pore diameter, and pore volume, however no total blocking can be observed. Modification 
by APTES also resulted in some decrease of the surface area, pore diameter, and pore volume whereas the indometacin loading on $\mathrm{MCM}-41 \mathrm{NH}_{2}$ led to the total pore filling.

The FT-IR spectra of all the studied mesoporous materials (not shown) are characterized by an intensive band at $1090 \mathrm{~cm}^{-1}$ which was due to the asymmetric stretching vibration of silica structure ( $\mathrm{Si}-\mathrm{O}-\mathrm{Si})$. Modification of MCM-41 by APTES resulted in the appearance of the band at $1540 \mathrm{~cm}^{-1}$, which was attributed to $\mathrm{N}-\mathrm{H}$ stretching vibrations of aminopropyl anchored

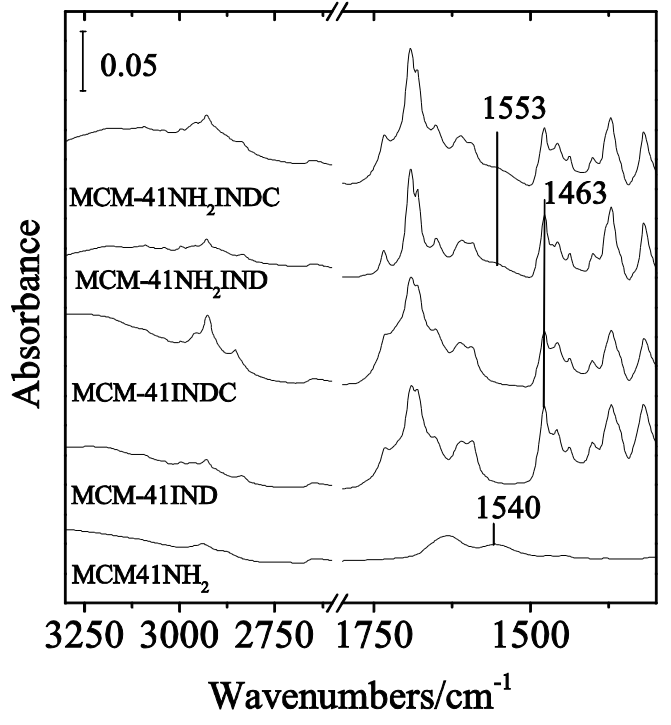

Fig. 3. ATR-FTIR spectra of amino-functionalized $\mathrm{MCM}-41 \mathrm{NH}_{2}$ and all indometacin loaded and carbopol-coated samples.

on the surface of the mesoporous carrier (Fig.3) [3,13]. The FT-IR spectra of indometacin loaded parent and amino-functionalized samples showed the band at $1463 \mathrm{~cm}^{-1}$ characteristic for phenyl bands due to the presence of indometacin molecules in the mesopore system. The presence of the band at $1552 \mathrm{~cm}^{-1}$ in the spectra of the aminofunctionalized and carbopol coated mesoporous silicas was indicative for the formation of a $\mathrm{COO}^{-}-\mathrm{NH}_{3}{ }^{+}$bond between the amino groups on the surface of the silica carrier and carboxylic groups from indometacin and carbopol (Fig. 3). Similar bond formation has been observed between carboxyl modified silica material and drug containing amino group (sulfadiazine) [23].

The ${ }^{13} \mathrm{C}$ CP MAS NMR spectra of MCM-41IND and $\mathrm{MCM}-41 \mathrm{NH}_{2}-\mathrm{IND}$ are presented in Fig. 4. The spectrum of MCM-41NH $\mathrm{N}_{2} \mathrm{IND}$ showed resonance signals (42.3 and $21.2 \mathrm{ppm}$ ) typical for carbonin the functional groups of the silica carrier. A broadening of the resonance signals registered in the spectrum of non-functionalized carrier (MCM-41IND) could be explained with the formation of dimers of two indometacin molecules by hydrogen bonds between their carboxyl groups (Fig.5a). This effect is not observed in the spectrum of functionalized carrier (MCM-41NH $\mathrm{N}_{2} \mathrm{IND}$ ) which could be explained by the predominant formation of hydrogen bonds between $\mathrm{NH}_{2}$ group of the carrier and $\mathrm{COOH}$ group of the indometacin molecule (Fig. 5b). There is no shift of the signal of carbon in carboxylic group of indometacin $\left(\mathrm{C}_{19}\right.$ at $\left.178.7 \mathrm{ppm}\right)$ in both spectra because of the participation of $\mathrm{COOH}$ groups in the formation on hydrogen bounds in both cases. Thus, the presence of functional groups of the carrier hindered the dimerization of indometacin that further could improve its loading. 


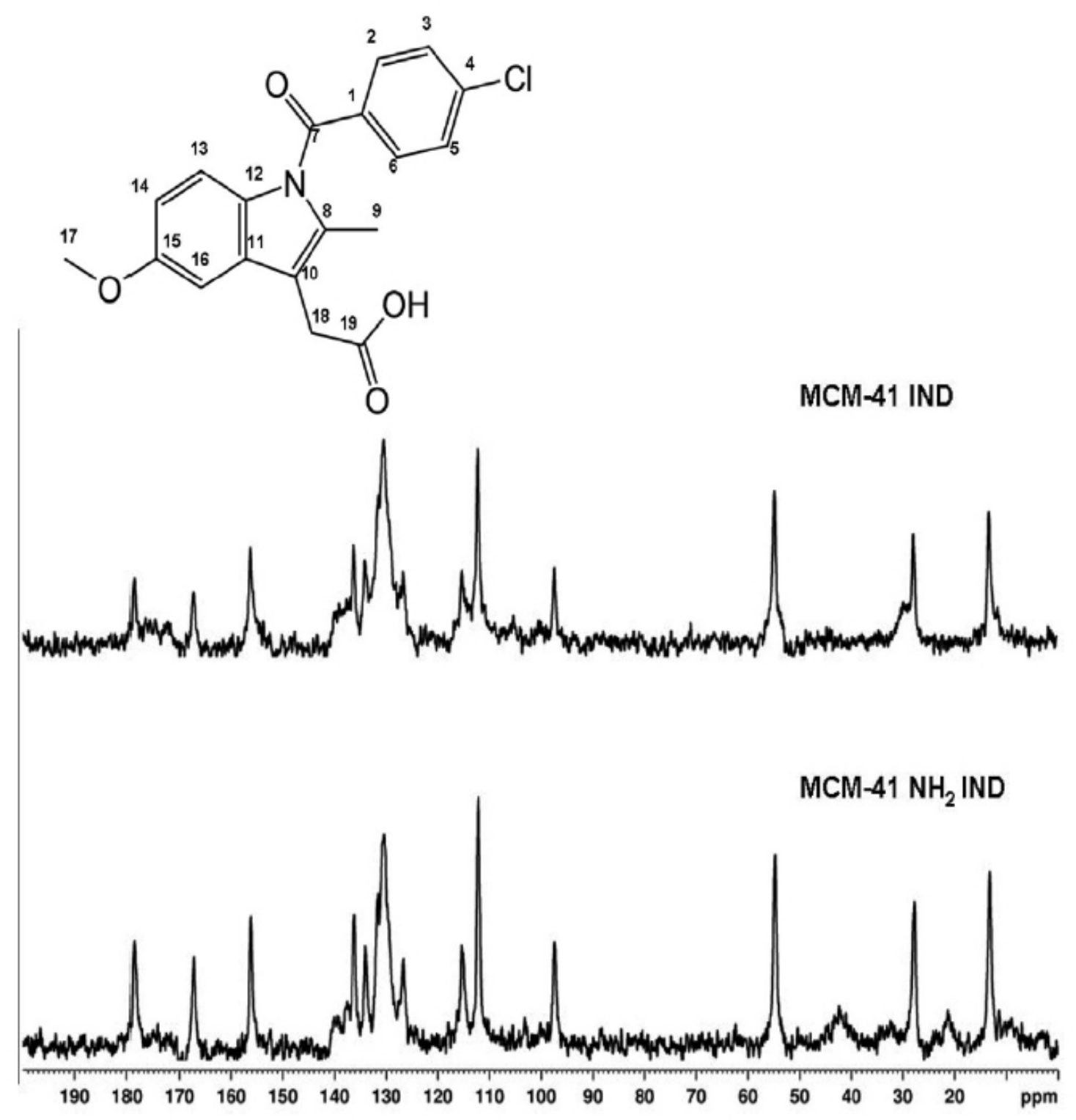

Fig. 4. ${ }^{13} \mathrm{C}$ NMR spectra of indometacin loaded parent and amino-functionalized materials (MCM-41IND and MCM-41NH $\left.{ }_{2} \mathrm{IND}\right)$.

The amino group, indometacin and carbopol content in the samples were quantified using thermogravimetric method. The amount of amino groups connected to the surface of MCM-41 support was 2.4 wt.\%. These data were in good accordance with former results and was confirmed also by the ninhydrin method [24]. The TG analysis determined the actual amount of drug in the carriers after correcting the curves by water and aminopropyl content (Fig. 6). The parent spherical MCM-41 showed lower adsorption capacity for indometacin (30 wt.\%), in comparison to its aminofunctionalized analogue (39 wt.\%). One possible reason was that the functionalization of mesoporous carrier results in higher drug loading capacity because of stronger interaction between the loaded drug molecule and the surface functional groups compared to the silanol groups of the unmodified silica carrier. Another reason for the lower indometacin loading in non-functionalized carrier could be indometacin dimerization as observed by NMR spectra. The bigger size of the dimers probably additionally hindered their 
incorporation into the pores of the carrier. The weight losses from carbopol coated MCM41INDC and MCM-41NH $\mathrm{INDC}_{2}$ were 37.0 and $50.6 \mathrm{wt} \%$, respectively (Fig. 6).
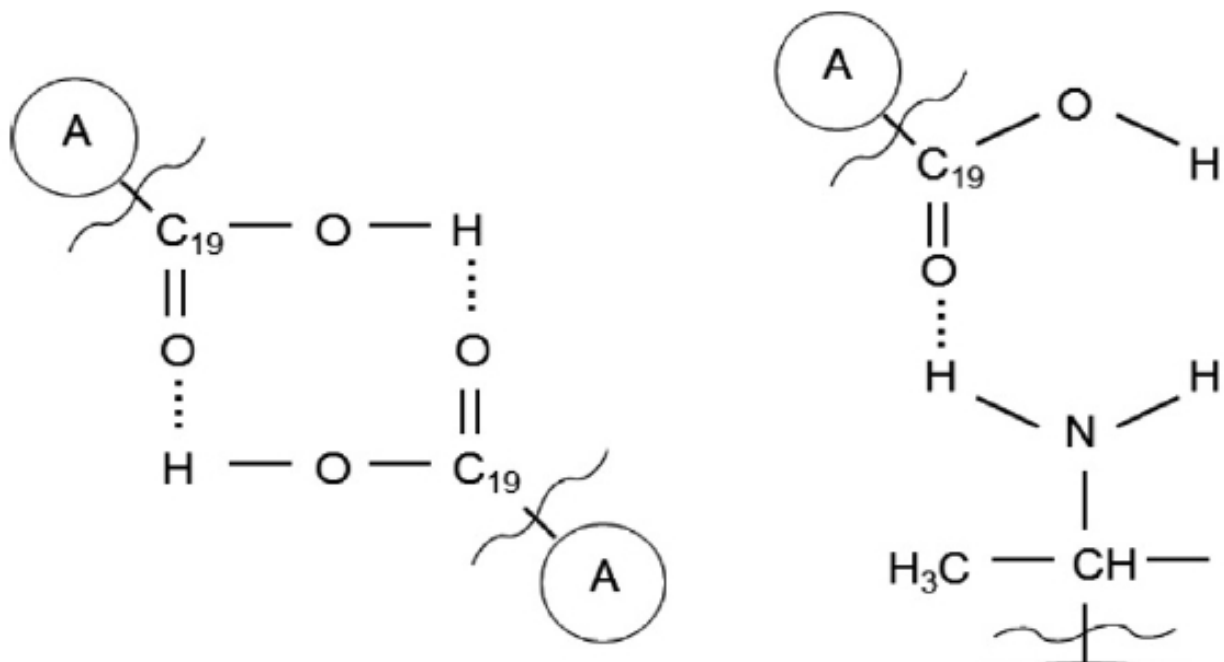

a
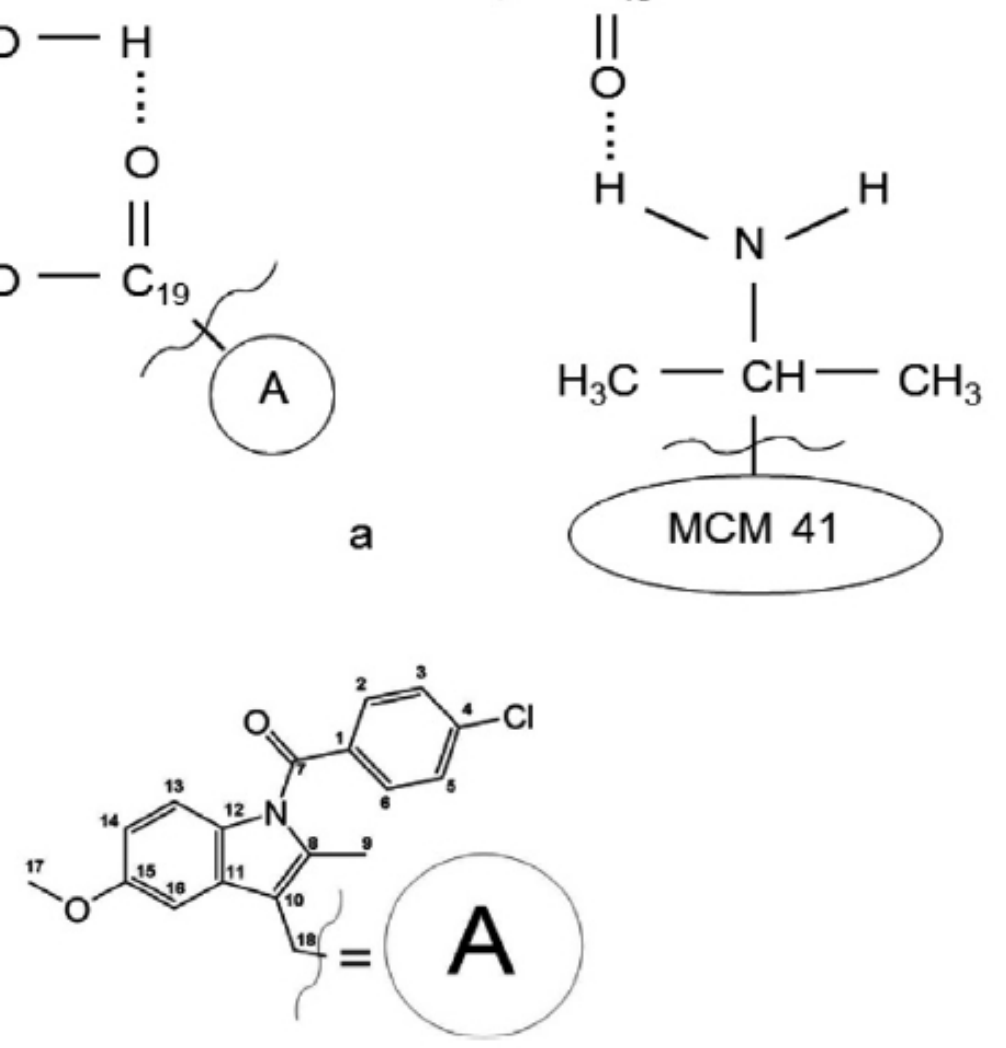

Fig. 5. Scheme representing hydrogen bonds between (a) two molecules of indometacin and (b) carboxyl groups of indometacin and amino groups of the functionalized $\mathrm{MCM}-41 \mathrm{NH}_{2}$ carrier.

The carbopol content was calculated by correcting the actual weight loss with aminopropyl and indometacin contents. In order to ensure correct deduction of indometacin amount, the concentration of the loaded indometacin was checked by measurement of the eventually loss indometacin during the coating procedure. The results showed that the loading of indometacin after coating was the same as it was in non-coated samples, suggesting that there was no indometacin diffusion out of the particles during the coating procedure. This fact was probably due to the high viscosity of the coating solution as well as the location of indometacin deeply in the pores. Thus, the content of carbopol in the coated samples was 7.0 and $11.6 \mathrm{wt} . \%$ for MCM41INDC and MCM-41NH $\mathrm{N}_{2}$ INDC, respectively. The higher amount of carbopol detected in MCM-41 $\mathrm{NH}_{2} \mathrm{INDC}$ was due to the stronger interaction between the functionalized external surface of the mesoporous carrier and the carbopol polymer.

TEM images of the parent and amino modified MCM-41 samples showed the formation of spherical particles with a size in the range of 100-400 nm (not shown). The size and the shape of drug loaded carbopol-coated particles are presented in Fig. 7. Particle size determination showed that indometacin loading and carbopol coating did not change neither the size of the MCM-41 and MCM-41NH2 materials nor the shape of the silica particles. 


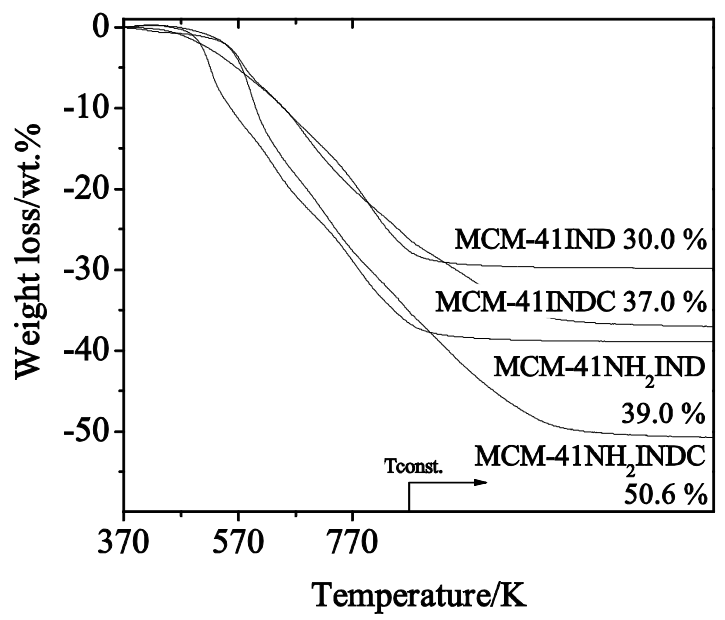

Fig. 6. TG curves of the indometacin loaded parent and the amino-functionalized materials (MCM-41IND and MCM-41NH $\mathrm{N}_{2} \mathrm{IND}$ ), and their carbopol coated analogues (MCM-41INDC and MCM-41NH $\mathrm{NINC}_{2}$ ). 

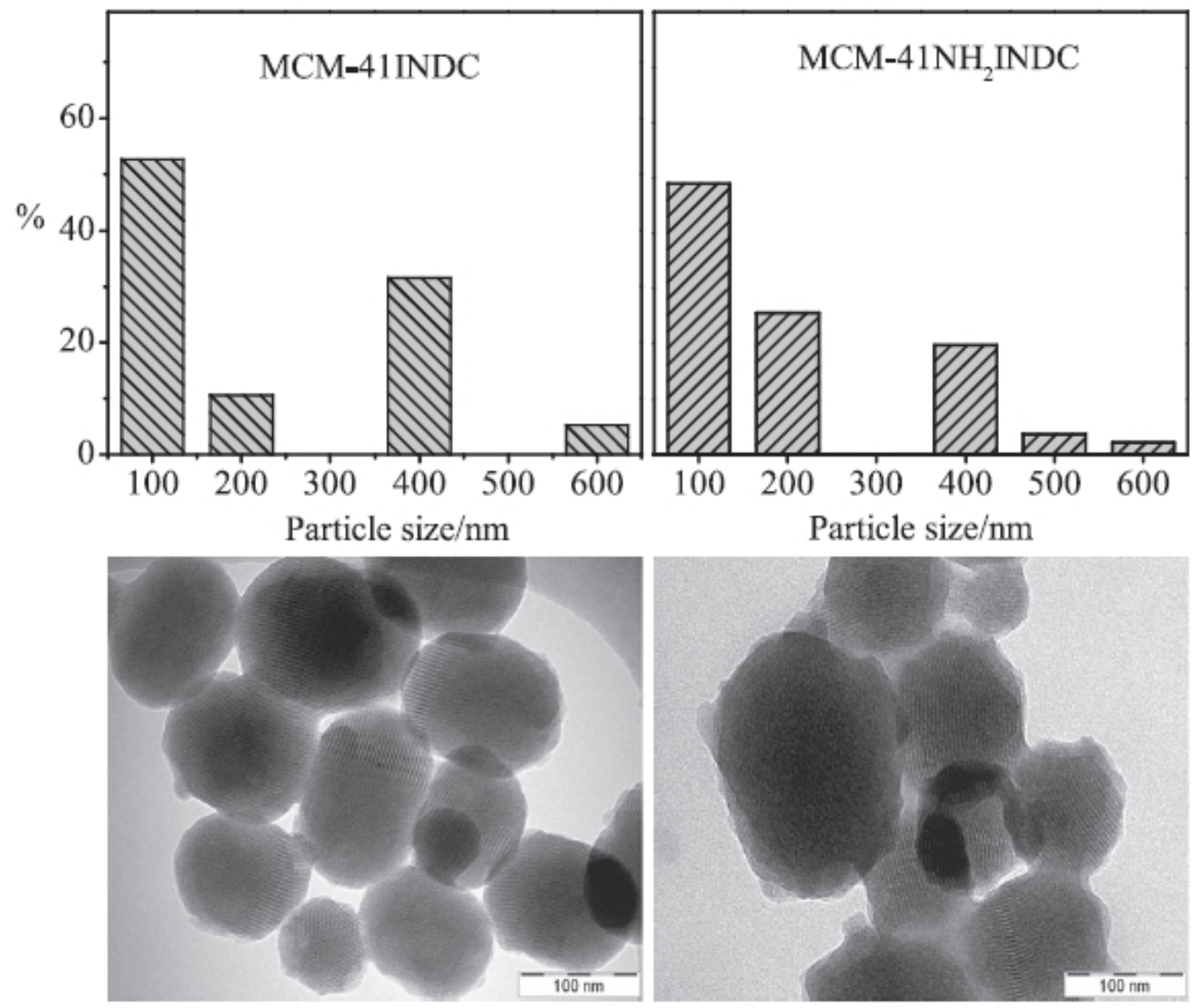

Fig. 7. Particle size distribution and TEM images of carbopol-coated MCM-41INDC and MCM-41 $\mathrm{NH}_{2} \mathrm{INDC}$ samples.

\subsection{Drug delivery}

The in vitro release process from both non-coated types of nanoparticles (MCM-41IND and MCM-41 $\mathrm{NH}_{2} \mathrm{IND}$ ) was investigated in two media, simulated gastric fluid with $\mathrm{pH}$ of 1.2 and simulated intestinal fluid with $\mathrm{pH}$ of 6.8. Slower drug release from both types of materials was observed in the simulated gastric fluid (Fig. 8). Within the first three hours approximately $15 \%$ and $28 \%$ of indometacin was released in acidic medium whereas the released indometacin in slightly alkaline medium was $80 \%$ and $99 \%$ from amino modified $\mathrm{MCM}-41 \mathrm{NH}_{2}$ and parent MCM-41 particles, respectively. The faster drug release in alkaline medium could be explained by two reasons. First, the deprotonation of the silanol groups in alkaline medium and a further repulsion between equally charged groups of carrier and indometacin was considered.

Consequently, the electrostatic repulsion promoted faster indometacin release out from the mesoporous nanoparticles. These results are in agreement with the study reporting in vitro release of sulfasalazine from trymethylammonium functionalized silica nanoparticles [25]. Second, the solubility of indometacin at this $\mathrm{pH}$ is higher than that at $\mathrm{pH}=1.2$ because the drug is a weak acid $\left(\mathrm{pK}_{\mathrm{a}}=4.5\right)$. Thus, this fact also promoted the faster release of indometacin in simulated intestinal fluid with $\mathrm{pH}$ of 6.8. However, independent of both phenomena, the rate of indometacin release in acid medium was still high which was undesired due to the damaging effect of indometacin on the gastric mucosa. In this view, two approaches were considered 
aiming to decrease the high initial indometacin release: the coating of the nanoparticles with carbopol and incorporation of indometacin in amino-functionalized carrier. The coating with carbopol did not change the release from non-functionalized particles, in particular $25 \%$ from carbopol coated vs. $28 \%$ from non-coated in the first $3 \mathrm{~h}$ (Fig. 8). However, the coating of amino-functionalized silica particles decreased significantly the release rate. As can be seen, $8 \%$ of indometacin was released from carbopol coated amino-functionalized particles in acidic medium in the first three hours versus $15 \%$ released from non-coated ones. These results were explained with the more efficient capping of particle pores in the case of functionalized MCM$41 \mathrm{NH}_{2}$ carrier due to the electrostatic bonds between carboxylic groups of carbopol and the free amino groups of the outer surface of the carrier. Hence, it was evidenced that coating of the aminofunctionalized silica particles with appropriate polymer decreased the initial indometacin release in the gastric fluid that in vivo could prevent the stomach mucosa.

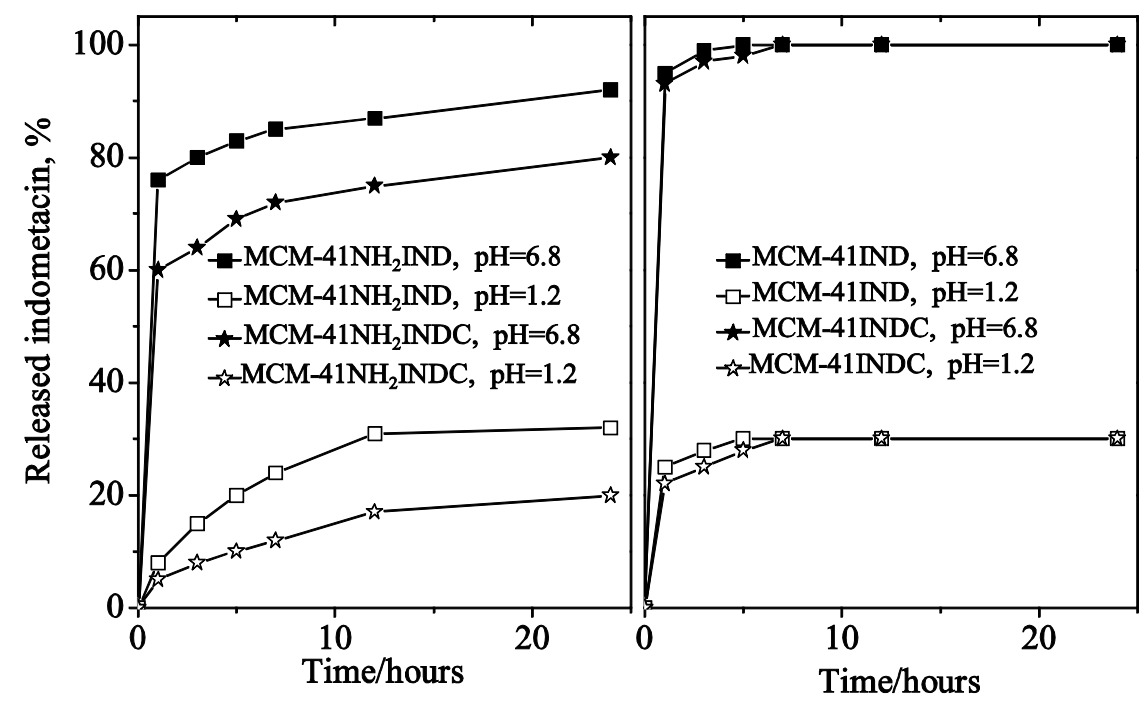

Fig. 8. In vitro release of indometacin from amino-functionalized non-coated $\mathrm{MCM}-41 \mathrm{NH}_{2} \mathrm{IND}$ and carbopol coated amino-functionalized MCM-41 $\mathrm{NH}_{2} \mathrm{INDC}$ particles; and parent non-coated MCM-41IND and carbopol coated MCM-41INDC particles in simulated gastric $(\mathrm{pH}=1.2)$ and simulated intestinal ( $\mathrm{pH}$ 6.8) fluids.

Another important finding was that independent with or without coating, slower drug release was observed from amino-functionalized nanoparticles compared to non-functionalized. Although both types possessed different loading (39\% and 30\%, respectively), this parameter was not considered responsible for the different release profiles. For example, the release profiles of functionalized (39\% loading) and non-functionalized (30\% loading) after $7 \mathrm{~h}$ in acid buffer became equal, suggesting that the loading had no influence on drug release rate. The lower release fromfunctionalized silicas was observed in both media leading to the conclusion that the use of amino-functionalized carrier contributed for the sustained indometacin release even at increasing $\mathrm{pH}$ as it occurred physiologically in gastrointestinal tract. The main factor that allowed the sustained release was probably the slow disruption of the electrostatic bonds between the functional groups of amino-functionalized carrier and indometacin. One more reason could be the fact that amino-functionalization made particles more hydrophobic that delayed the penetration of the release media into the pores. The later additionally hindered the drug diffusion out of the pores. Consequently, the sustained release profile of the drug indicated that the particles could be considered as a platform for the development of a once daily administered dosage form. 


\subsection{Cytotoxicity of the carriers and the drug loaded silica particles}

The cytotoxic activity of the carriers and the drug loaded nanoparticles was evaluated in two human cell lines after $72 \mathrm{~h}$ continuous exposure using the MTT dye-reduction assay. First, parent and the amino modified carriers were evaluated for eventual cytotoxic effect. The results showed that both placebo carrier suspensions were practically devoid of cytotoxic and antiproliferative effects in the model cellular populations suggesting their safety (Fig. 9).

The well established ulcerogenic effect of indometacin on gastrointestinal mucosa and the related complications constitute a major drawback limiting its clinical usefulness. While it has been well recognized that much of the adverse effects are attributable to the inhibition of prostaglandin synthesis [26,27], new experimental data has been gathered to support the possible role of additional toxicodynamic mechanisms [28-30]. Non-steroid antiinflammatory drugs like indometacin, have been documented to exert direct cytotoxicity mediated by alteration in cell membrane integrity and functions, induction of free radical formation and lipid peroxidation, and recruitment of cell death signaling pathways via cyclooxygenase-independent mechanisms (28-30). Thus the toxic effects on the gastrointestinal tract tissues, which in case of oral treatment are exposed to high initial levels of indometacin are mediated by both decreased levels of gastroprotective prostaglandins and direct noxious effects on gastric mucosal cells. Thus, the incorporation of indometacin into the mesoporous nanoparticles would be beneficial not only for pharmacokinetic point of view, but also could contribute to decreased exposure of the non-target gastrointestinal tissues to the noxious activity of indometacin. On these ground a comparative assessment of the cytotoxic effects of free indometacin vs. indometacin loaded in the nanoparticles was performed (Fig. 10). The free indometacin showed superior higher cytotoxicity than drug-loaded mesoporous materials as evident from the cell survival data.
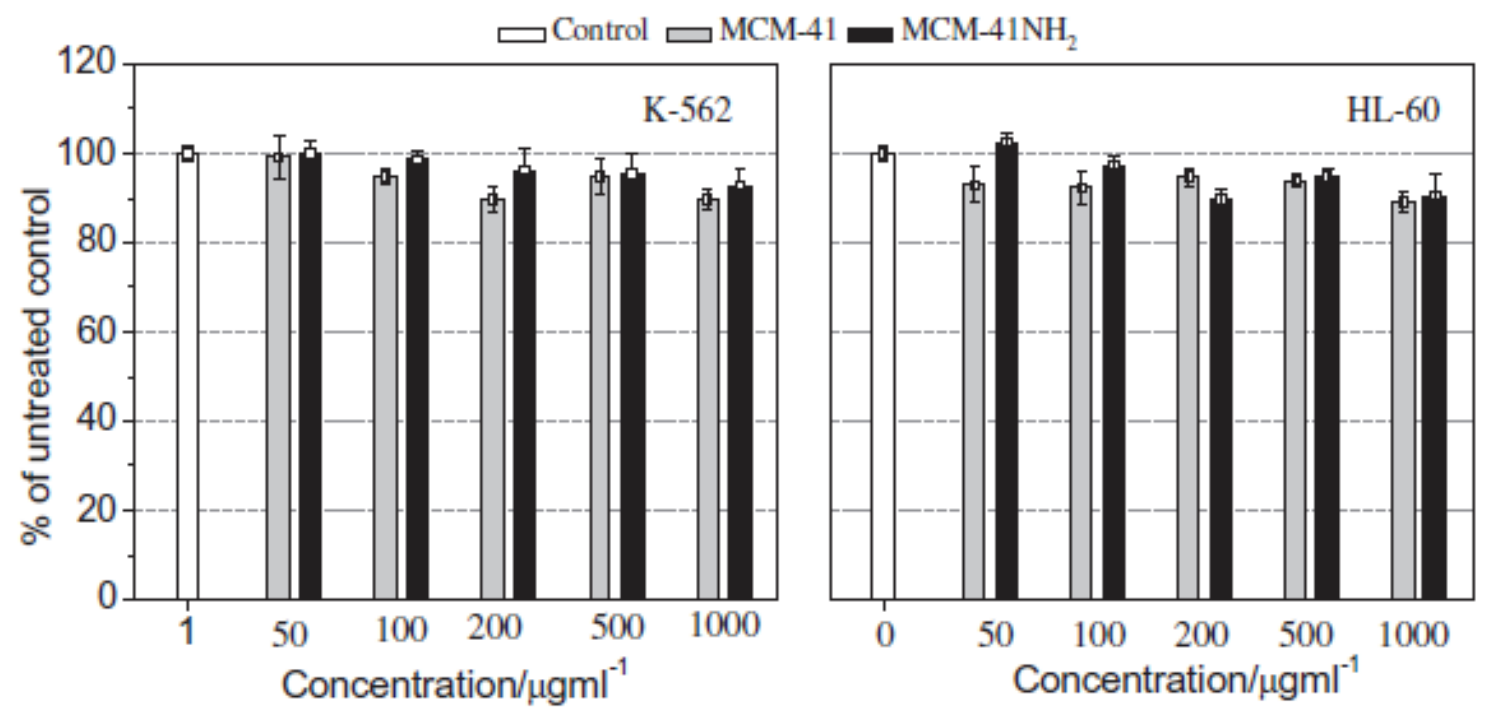

Fig. 9. In vitro cytotoxicity of MCM-41 and MCM-41NH $\mathrm{N}_{2}$ on K-562 and HL-60 cell lines. 

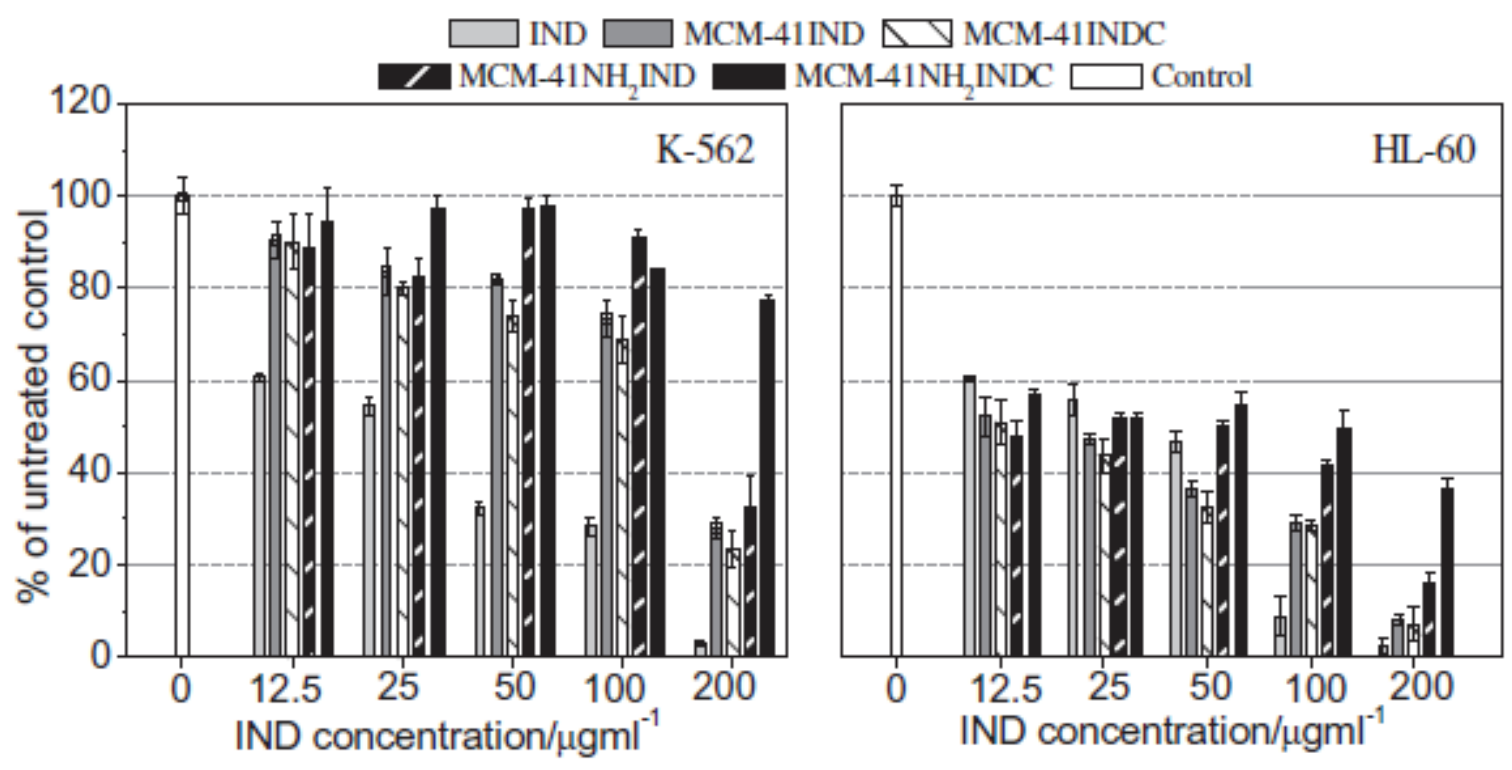

Fig. 10. In vitro cytotoxicity of indometacin loaded MCM-41IND, MCM-41NH $\mathrm{N}_{2} \mathrm{IND}$ and their carbopol-coated analogues (MCM-41INDC and MCM-41NH ${ }_{2}$ INDC) on K-562 and HL-60 cell lines.

The increase of the indometacin concentration increased cytotoxicity of almost all the samples except for carbopol coated amino-unctionalized ones. These particles showed lower cytotoxicity even at the highest concentration that correlated well with the slower indometacin release from the carbopol-coated particles (Fig. 8).

Thus, the modified release from the carriers was characterized by significant amelioration of intrinsic cytotoxicity of indomethacin. These findings indicate that such carriers would greatly decrease the propensity of the drug to interact with nonpharmacological targets, and hence an improvement of its safety profile could be expected. Moreover, the mesoporous systems themselves proved to be fully devoid of cytotoxic potential which is of paramount importance for their potential utility as pharmaceutical excipients.

\section{Conclusion}

Nanosized spherical mesoporous MCM-41 particles were prepared and modified by aminopropyl groups. Amino-functionalization of mesoporous MCM-41 carrier led to higher degree of indometacin loading, in particular approximately $390 \mathrm{mg} / \mathrm{g}$ compared to $300 \mathrm{mg} / \mathrm{g}$ in non-functionalized MCM-41. The coating of amino-functionalized and drug loaded MCM-41 particles with carbopol significantly decreased the initial burst release of indometacin that could prevent the damage of gastrointestinal mucosa after oral administration. Another important advantage of the carbopol coating is the significantly lower cytotoxicity of the coated indometacin loaded particles compared with the free indometacin.

\section{Acknowledgements}

Financial support by the Bulgarian-Hungarian Inter-academic Exchange Agreement is greatly acknowledged. The discussion of the NMR spectra by Dr. P. Shestakova is acknowledged. 


\section{References}

[1] M. Vallet-Regi, A. Ramila, R.P. del Real, J. Perez-Pariente, Chem. Mater. 13 (2001) 308311.

[2] Sh. Wang, Microporous Mesoporous Mater. 117 (2009) 1-9.

[3] P. Horcajada, A. Ramia, G. Ferey, M. Vallet-Regi, Solid State Sci. 8 (2006) 1243-1249.

[4] M. Manzano, V. Aina, C.O. Arean, F. Balas, V. Cauda, M. Colilla, M.R. Delgado, M. ValletRegi, Chem. Eng. J. 137 (2008) 30-37.

[5] B.G. Trewyn, I.I. Slowing, S. Giri, H.-T. Chen, V.S.-Y. Lin, Acc. Chem. Res. 40 (2007) 846-853.

[6] I. Slowing, J.L. Vivero-Escoto, C.W. Wu, V.S. Lin, Adv. Drug Deliv. Rev. 60 (2008)

$1278-1288$.

[7] M. Manzano, M. Colilla, M. Vallet-Regi, Exp. Opin. Drug Deliv. 6 (2009) 1383-1400.

[8] G. Wang, A.N. Otuonye, E.A. Blair, K. Denton, Zh. Tao, T. Asefa, J. Solid State Chem. 182 (2009) 1649-1660.

[9] J.C. Doadrio, E.M.B. Sousa, I. Izquierdo-Barba, A.L. Doadrio, J. Perez- Pariente, M. ValletRegi, J. Mater. Chem. 16 (2006) 462-466.

[10] E.I. Basaldella, M. Legnoverde, J. Sol-Gel Sci. Technol. 56 (2010) 191-196.

[11] C.Y. Lai, B.G. Trewyn, D.M. Jeftinija, K. Jeftinija, S. Xu, S. Jeftinija, V. Lin, J. Am. Chem. Soc. 125 (2003) 4451-4459.

[12] Y.-J. Yang, X. Tao, Q. Hou, Y. Ma, X.-L. Chen, J.-F. Chen, Acta Biomater. 6 (2010) 3092-3100.

[13] P. De Muth, M. Hurley, Ch. Wu, S. Galanie, M.R. Zachariah, P. De Shong, Microporous Mesoporous Mater. 141 (2011) 128-134.

[14] Q. He, Y. Gao, L. Zhang, Zh. Zhang, F. Gao, X. Ji, Y. Li, J. Shi, Biomaterials 32 (2011) 7711-7720.

[15] F. Chen, Y. Zhu, Microporous Mesoporous Mater. 150 (2012) 83-89.

[16] C.-Y. Hong, X. Li, C.-Y. Pan, J. Mater. Chem. 19 (2009) 5155-5160.

[17] Q. Gao, Y. Xu, D. Wu, Y.H. Sun, X.A. Li, J. Phys. Chem. C 113 (2009) 12753-12758.

[18] Y.-Z. You, K. Kalebaila, S. Brock, D. Oupichy, Chem. Mater. 15 (2003) 3385-3394.

[19] C.J. Shorrock, W.D. Rees, Gut 33 (1992) 164-169.

[20] S.K. Shrivastava, D.K. Jain, P. Trivedi, Pharmazie 58 (2003) 389-391.

[21] T. Ogiso, M. Iwaki, T. Tanino, T. Nagai, Y. Ueda, O. Muraoka, G. Tanabe, Biol. Pharm. Bull. 19 (1996) 1178-1180.

[22] S. Huh, J.W. Wiench, J.-C.h. Yoo, M. Pruski, V.S.-Y. Lin, Chem. Mater. (2003) $4247-$ 4256.

[23] M. Popova, A. Szegedi, I. Kolev, J. Mihaly, B. Tzankov, N. Lambov, K. Yoncheva, Int. J. Pharm. 436 (2012) 778-785.

[24] A. Szegedi, M. Popova, J. Solid State Chem. 194 (2012) 257-263.

[25] C.H. Lee, L.W. Lo, C.W. Mou, C.S. Yang, Adv. Funct. Mater. 18 (2008) 3283-3292.

[26] T. Kaneko, H. Matsui, O. Shimokawa, A. Nakahara, I. Hyodo, J. Gastroenterol. 42 (2007) 939-946.

[27] S.J. Konturek, P.C. Konturek, T. Brzozowski, J. Physiol. Pharmacol. 56 (Suppl. 5) (2005) $5-31$.

[28] J.K. Chang, G.J. Wang, S.T. Tsai, M.L. Ho, Connective Tissue Res. 46 (2005) 200-210.

[29] Y. Naito, T. Yoshikawa, Redox Rep. 11 (2006) 243-253.

[30] A. Tan, H. Nakamura, N. Kondo, M. Tanito, Y.W. Kwon, M.K. Ahsan, H. Matsui, M. Narita, J. Yodoi, Free Radical Res. 41 (2007) 861-869. 